\title{
Standardization of Cluster Members Processes
}

\author{
Tomas Cechura, Tomas Broum, Antonin Miller, Jana Kleinova and Michal Simon \\ University of West Bohemia, The Faculty of Mechanical Engineering, Department of Industrial Engineering and Management, \\ Univerzitni 8, Pilsen, 30614, Czech Republic \\ tcechura@kpv.zcu.cz, tbroum@kpv.zcu.cz, amiller@kpv.zcu.cz, kleinova@kpv.zcu.cz, simon@kpv.zcu.cz
}

\begin{abstract}
The aim of the paper is to create a methodology to support decision making for dealing with processes within a cluster. First the article focuses on a list of potentially suitable processes for a coordinated cluster approach, then the relevant process parameters are defined. The main part is to determine the conditions and criteria for determining the suitability of the process for coordination within the cluster. Questions were created based on these criteria. According to responses to these questions the classification matrix was created. This resulted in the recommendation for dealing with the process. The outcome is the classification matrix which recommends how to deal with the process. The whole procedure has been applied to specific examples of processes.
\end{abstract} matrix

Index Terms - process, cluster, standardization, classification,

\section{Introduction}

A business cluster is "a geographic concentration of interconnected businesses, suppliers, and associated institutions in a particular field." [1] Clusters are considered to increase the productivity with which companies can better compete on the market. They usually have a large number of participants and a 'cluster core'. This expression is used for highly specialized companies in the same branch. Geographical proximity can create either competition or even efficient cooperation. This may sound like a paradox, but it is true. Intensive communication leads to growth of trust and creates new personal contacts, formal and informal networks, closed contractor-customer relationships, cooperation on projects, etc. Clusters usually look like one big unit from the outside. A cluster is capable of tying together opposing companies' advantages - the flexibility of the small ones and the power of the big ones.

The aim of this paper is to create a method to determine the appropriate processes for a coordinated cluster approach. A coordinated cluster approach means jointly ensuring processes for individual cluster members.

\section{Analysis and Selection of Processes for Joint Cluster Approach}

This section focuses on the selection of suitable processes for a joint cluster approach. This is followed by an analysis of parameters of these processes.

Selection of appropriate processes for joint cluster approach. Not all the processes in companies can be used for a joint cluster approach. Some of them have to be eliminated. Reasons for exclusion of individual processes are e.g.:
- Processes which deal with confidential data of individual members (e.g. wages).

- Unwillingness to participate in the joint cluster procedure (unwillingness to have central control of the processes such as some of the production processes).

- Processes in which joint cluster approach would be ineffective (e.g. technical preparation of the production).

- Processes with geographical barrier (e.g. some of the processes of production).

Based on the analysis the processes suitable for a joint cluster approach were selected. Processes were selected which are usually solved through outsourcing and furthermore processes which are common in large companies. Table 1 shows an example of the processes selected for a joint cluster approach.

Table 1: Processes selected as suitable for joint cluster approach.

\begin{tabular}{|c|c|}
\hline Field & Processes \\
\hline Finance, controlling & $\begin{array}{l}\text { - } \quad \text { Financial Accounting } \\
\text { - } \quad \text { Cost Accounting etc. }\end{array}$ \\
\hline Management & $\begin{array}{ll}\text { - } & \text { Evaluation of projects } \\
\text { - } & \text { Evaluation of products }\end{array}$ \\
\hline Other processes & $\begin{array}{ll}\text { - } & \text { Legal service } \\
\text { - } & \text { Corporate culture etc. }\end{array}$ \\
\hline
\end{tabular}

Analysis of parameters of processes suitable for a joint cluster approach. First, substantial parameters regarding the general processes were determined. Then these parameters were specified for individual identified processes. An overview of the parameters is shown in Table 2.

Table 2: Summary of parameters of the processes suitable for a joint cluster approach.

\begin{tabular}{|c|l|}
\hline Field & \multicolumn{1}{|c|}{ Processes (parameters) } \\
\hline $\begin{array}{c}\text { Finance, } \\
\text { controlling }\end{array}$ & $\begin{array}{l}\text { - Financial Accounting (depending on the } \\
\text { organizational-legal form of company) } \\
\text { - Cost Accounting (detail, periodicity) etc. }\end{array}$ \\
\hline Management & $\begin{array}{l}\text { - Evaluation of projects (detail, evaluation criteria) } \\
\text { Evaluation of products (detail, evaluation } \\
\text { criteria) }\end{array}$ \\
\hline $\begin{array}{c}\text { Other } \\
\text { processes }\end{array}$ & $\begin{array}{l}\text { - Legal service (range) } \\
\text { Corporate culture (range) etc. }\end{array}$ \\
\hline
\end{tabular}




\section{Defining Constraints and Criteria for Selecting Appropriate Processes for the Joint Cluster Approach}

In this section are defined significant constraints and criteria for selecting appropriate processes for a joint coordinated cluster approach. Further processes are divided into four groups according to their significance and feasibility.

Defining constraints and criteria. Determination of the relevant constraints and criteria is important for determining the suitability of processes for a joint cluster approach. Below are given constraints of the processes suitable for a joint cluster approach.

- The same requirements for the process (which can vary in the extent of realization)

- The need of ensuring specific process

- The willingness of cluster members to participate in a joint cluster approach

- The need for standardization for the cluster members (some processes);

- Availability of process (e.g. geographical)

- The total profit exceeds the cost of coordination

Criteria can be either qualitative or quantitative, and often can be mutually contradictory. The selection is usually done according to basic criteria: Price, Quality, Time.

Division of processes. There are two especially important main aspects for dividing processes. If we want to determine whether the process is suitable for a joint cluster approach, we have to identify several basic groups of processes. The first aspect is whether a member of the cluster can deal with a process within the company (or cluster), or if it is more appropriate or necessary to deal with this process externally (outsourcing). Another significant aspect is the significance of the process for the entire cluster, and thus for joint cluster approach.

These aspects define two groups of criteria:

- Feasibility of processes within the cluster

Here we decide whether the process will be dealt with within the cluster or outsourced.

- Significance of processes within the cluster

Here we decide on the suitability of the process for joint cluster approach.

The two aspects also define four groups of processes:

- Individual-internal

Processes suitable for solving individually by each cluster member and therefore unsuitable for joint cluster approach. The processes are not suitable for outsourcing.

- Individual -outsourcing

Processes suitable for solving individually by each cluster member and therefore unsuitable for joint cluster approach. The processes are suitable for outsourcing.
- Coordinated -internal

Processes suitable for joint cluster approach. The processes are not suitable for outsourcing.

- Coordinated-outsourcing

Processes suitable for joint cluster approach. The processes are suitable for outsourcing.

The groups of processes are shown in Fig 1.

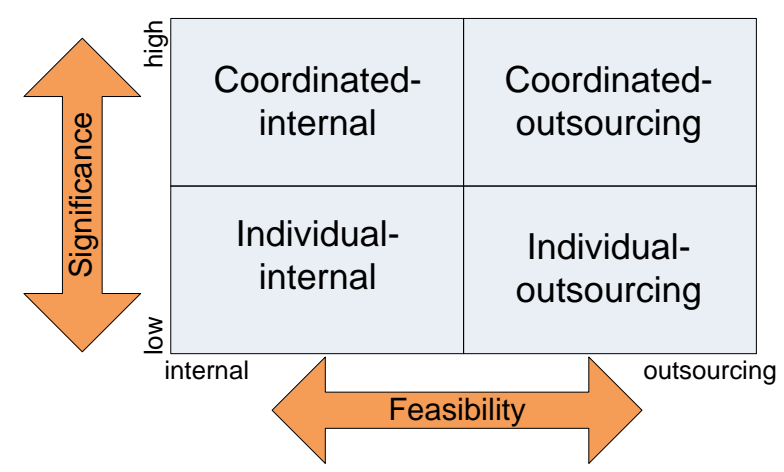

Figure 1: The matrix of fundamental groups of processes

Criteria of feasibility of processes within the cluster:

- Cost of creation of process - Return on investment (if the cluster is able to provide process itself cheaply)

- Qualification requirements of employees

- The existence of a suitable provider

- Willingness to outsource

- Value added to the product

Criteria of significance of processes within the cluster:

- Operating costs

- The cost of creation

- How many members of the cluster deal with process

- Willingness to solve process together

- Benefits of joint cluster approach for the cluster

- Differences in the claims of cluster members to the process

- Geographical position of cluster members

- The level of information sharing

- The importance of response rate

- The existence of a suitable coordinator

Questions were created on the basis of the criteria. The questions concerning the significance of the process for the cluster, including the possible answers, are in Table 3 . The questions concerning the feasibility of the process, including possible answers, are in Table 4. A process is assigned to the appropriate group of processes by answering the questions see Fig. 1. 
Table 3: Questions and answers - significance criteria category

\begin{tabular}{|c|c|c|c|c|c|c|}
\hline \multicolumn{3}{|r|}{ Questions } & \multicolumn{4}{|c|}{ Possible answers } \\
\hline \multirow{10}{*}{ 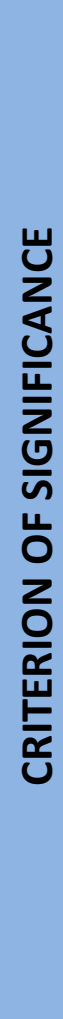 } & 1 & What is the operating cost of the process? & very high & high & low & very low \\
\hline & 2 & $\begin{array}{l}\text { Is the cost of the creation of a } \\
\text { coordinated process acceptable? }\end{array}$ & yes & rather yes & rather no & no \\
\hline & 3 & $\begin{array}{l}\text { How many members of the cluster deals } \\
\text { with the process? }\end{array}$ & all & majority & minority & sporadically \\
\hline & 4 & $\begin{array}{l}\text { Are cluster members willing to deal with } \\
\text { the process together? }\end{array}$ & yes & rather yes & rather no & no \\
\hline & 5 & $\begin{array}{l}\text { How high benefit is for joint coordination } \\
\text { of process within the cluster? }\end{array}$ & significant & satisfying & minimum & insignificant \\
\hline & 6 & $\begin{array}{l}\text { How significant are the differences of } \\
\text { cluster members in the claims of process? }\end{array}$ & acceptable & $\begin{array}{c}\text { rather } \\
\text { acceptable }\end{array}$ & $\begin{array}{l}\text { rather } \\
\text { unacceptable }\end{array}$ & unacceptable \\
\hline & 7 & $\begin{array}{l}\text { Is the geographic location of cluster } \\
\text { members appropriate to ensure the } \\
\text { process? (are they located close to each } \\
\text { other) }\end{array}$ & suitable & rather suitable & not suitable & irrelevant \\
\hline & 8 & $\begin{array}{l}\text { What is the level of information sharing } \\
\text { for successful implementation and } \\
\text { coordination of the process? }\end{array}$ & sufficient & $\begin{array}{l}\text { rather } \\
\text { sufficient }\end{array}$ & $\begin{array}{l}\text { rather } \\
\text { insufficient }\end{array}$ & insufficient \\
\hline & 9 & Is the response rate acceptable? & yes & $\begin{array}{c}\text { yes with } \\
\text { objections }\end{array}$ & irrelevant & no \\
\hline & 10 & $\begin{array}{l}\text { Is there appropriate coordinator for the } \\
\text { process? }\end{array}$ & yes & $\begin{array}{l}\text { yes, minor } \\
\text { objections }\end{array}$ & $\begin{array}{c}\text { yes, significant } \\
\text { objections }\end{array}$ & no \\
\hline
\end{tabular}

Table 4: Questions and answers - feasibility criteria category

\begin{tabular}{|c|c|c|c|c|c|c|}
\hline \multicolumn{3}{|r|}{ Questions } & \multicolumn{4}{|c|}{ Possible answers } \\
\hline \multirow{6}{*}{ 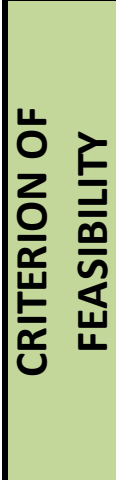 } & 1 & $\begin{array}{l}\text { Is it profitable to realize the process } \\
\text { ourselves? }\end{array}$ & no & rather no & rather yes & yes \\
\hline & 2 & $\begin{array}{l}\text { Is our professional level sufficient to } \\
\text { ensure the process? }\end{array}$ & insufficient & $\begin{array}{c}\text { rather } \\
\text { insufficient }\end{array}$ & rather sufficient & sufficient \\
\hline & 3 & $\begin{array}{l}\text { Is there a suitable supplier for the } \\
\text { process? }\end{array}$ & $\begin{array}{c}\text { excellent } \\
\text { availability }\end{array}$ & $\begin{array}{c}\text { medium } \\
\text { availability }\end{array}$ & $\begin{array}{c}\text { difficult } \\
\text { availability }\end{array}$ & does not exist \\
\hline & 4 & Are we willing to outsource? & all & majority & minority & no \\
\hline & 5 & Is the need of the process steady in time? & no & rather no & rather yes & yes \\
\hline & 6 & $\begin{array}{l}\text { Does the process increase the value of the } \\
\text { product? }\end{array}$ & no & partly & irrelevant & yes \\
\hline
\end{tabular}

\section{Application of the Method to Selected Processes}

In the previous section the set of questions were created. By selection of answers to specific questions the recommended solution is shown in the matrix. This matrix will recommend the user whether or not to outsource the process and whether the process is suitable for a joint cluster approach. The matrix was verified on six processes: Providing communication phone, Manufacturing the product - own production, Catering, Taxes, Recruitment, Testing. (see Fig. 2) 


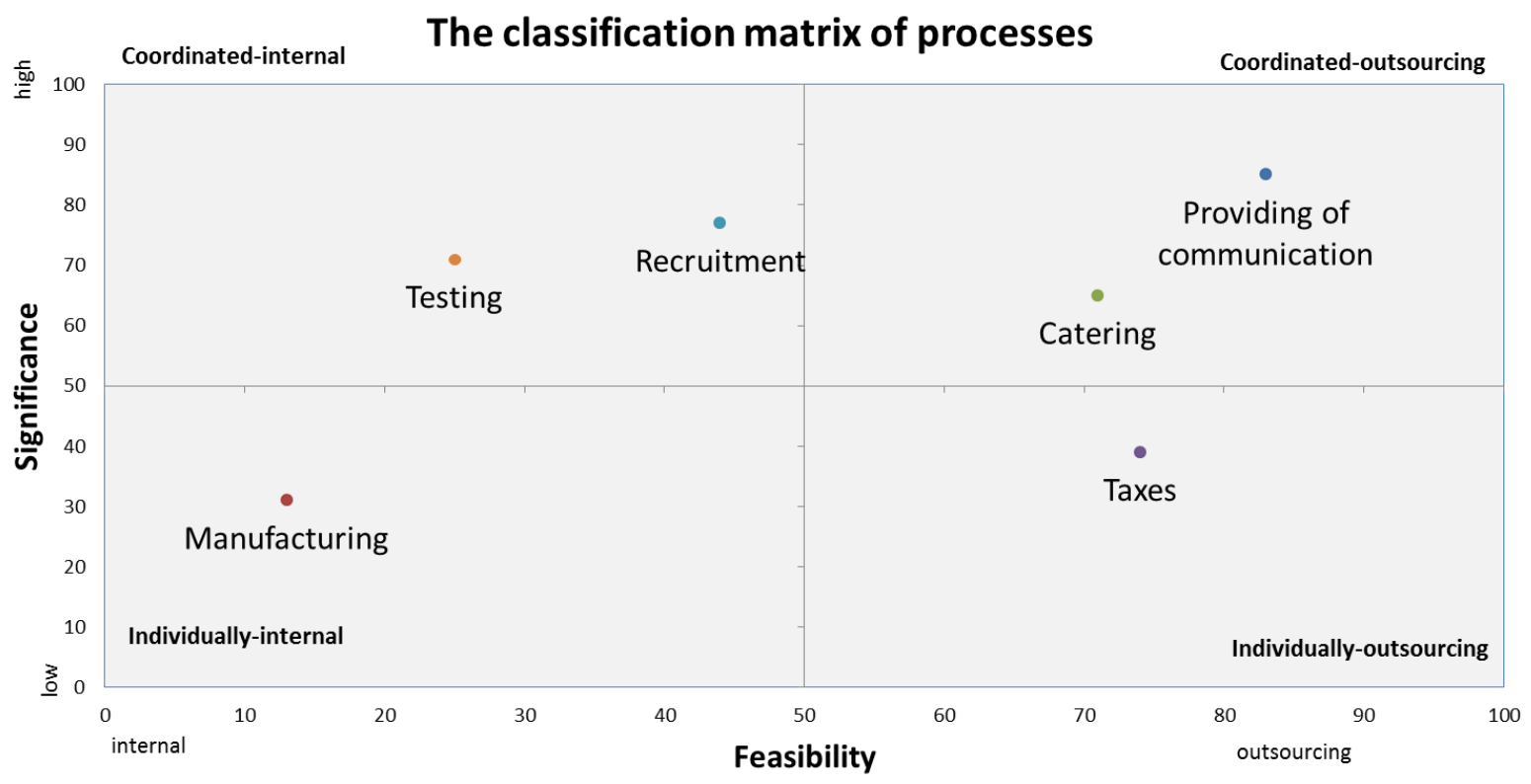

Figure 2: Example of application of the classification matrix

\section{Conclusions}

The aim of this paper was to create a method to determine the appropriate processes for a joint cluster approach. This aim was achieved by creating a classification matrix of processes. The benefit of this work is the recommendation of processes for joint coordination within the cluster. This paper seeks to promote the main purpose of this work, which is the cost savings of individual cluster members, through their membership in the cluster. Cost savings will lead to greater competitiveness of individual members and defend the idea of the cluster.

\section{Acknowledgements}

This paper was supported by the Internal Grant Agency of the University of West Bohemia, project No. SGS-2012063 - "Integrated design of manufacturing system as metaproduct with a multidisciplinary approach and with use of elements of virtual reality."

\section{Reference}

[1] http://www.distil.com.au/blog/285-business-clusters-definition-abenefits-of-business-clusters, (2010-12-07). 